\title{
PORQUE O MUNDO É POSSÍVEL: A BATALHA DE LINGUAGEM NAS SOCIEDADES MUNDIALIZADAS
}

\section{BECAUSE THE WORLD IS POSSIBLE: THE BATTLE OF LANGUAGE IN GLOBALIZED SOCIETIES}

\section{PORQUE EL MUNDO ES POSIBLE: LA BATALLA DEL LENGUAJE EN LAS SOCIEDADES GLOBALIZADAS}

\section{Eguimar Felício Chaveiro ${ }^{1}$}

Resumo: A premissa central deste trabalho pode ser assim enunciada: toda transformação social age sobre a linguagem; toda mudança de linguagem interfere nas relações sociais. A linguagem, especificamente no que se refere ao trabalho intelectual e pedagógico, detidamente nos três componentes centrais - leitura, escrita e desenvolvimento do raciocínio - expressa e constitui o tempo, o tempo que a constitui. A questão central situa-se em avaliar como, dentro e fora da escola, a batalha de linguagem como uma batalha de vida, é acometida pela estrutura das sociedades mundializadas. Dizeres laboratoriais, esotéricos, metafísicos, irônicos, militarizados ganham a cena deste tempo, geram perplexidades e desafiam os que consideram os preceitos da liberdade, da autonomia e da integridade ética, valores para fecundar as relações humanas. Esse desafio encontra na própria linguagem a dimensão infinita e aberta; é o possível humano. O infinito simbólico é a chama e o fermento do infinito humano. Trata-se de produzir sentidos para o que se vê, sente, palpita, interroga. Este é o maior desígnio: pensar e viver.

Palavras-chave: sociedades mundializadas; batalha de linguagem; dicção contemporânea; Infinito humano.

\begin{abstract}
The central premise of this work can be stated thus: all social transformation acts on language; every change of language interferes in the social relations. The language, specifically with regard to intellectual and pedagogical work, narrowly focused on the three central components - reading, writing and the development of reasoning - expresses and constitutes the time, the time that constitutes it. The central question is to evaluate how, within and outside school, the battle of language as a battle of life is affected by the structure of globalized societies. Laboratory, esoteric, metaphysical, ironic, militarized sayings win the scene of this time, generate perplexities and challenge those who consider the precepts of freedom, autonomy and ethical integrity of values to fertilize human relations. This challenge finds in the language itself the infinite and open dimension; it is the possible human. The symbolic infinity is the flame and the yeast for the human infinity. It is about producing meanings for what one sees, feels, throbs, questions. This is the greatest purpose: to think and to live.
\end{abstract}

Keywords: globalized societies; battle of language; contemporary diction; human infinity.

\footnotetext{
${ }^{1}$ Professor Titular nos Cursos de Graduação e Pós-Graduação Stricto Sensu em Geografia do Instituto de Estudos Socioambientais da Universidade Federal de Goiás - IESA/UFG. Coordenador do Grupo de Pesquisa e Extensão Espaço, Sujeito e Existência - Dona Alzira. E-mail: eguimar@ hotmail.com
} 
Resumen: La premisa central de este trabajo puede expresarse así: toda transformación social actúa sobre el lenguaje; todo cambio de idioma interfiere con las relaciones sociales. El lenguaje, específicamente con respecto al trabajo intelectual y pedagógico, detenido estrechamente en los tres componentes centrales: lectura, escritura y desarrollo del razonamiento, expresa y constituye el tiempo, el tiempo que lo constituye. La pregunta central es evaluar cómo, dentro y fuera de la escuela, la estructura de las sociedades globalizadas afecta la batalla del lenguaje como batalla de la vida. Los dichos de laboratorio, esotéricos, metafísicos, irónicos, militarizados, toman la escena de este tiempo, generan perplejidades y desafían a aquellos que consideran los preceptos de libertad, autonomía e integridad ética como valores para fertilizar las relaciones humanas. Este desafío encuentra en el lenguaje mismo la dimensión infinita y abierta; es el posible humano. El infinito simbólico es la llama y la levadura para el infinito humano. Se trata de producir significados para lo que uno ve, siente, palpita, pregunta. Este es el mayor propósito: pensar y vivir.

Palabras clave: sociedades globalizadas; batalla del lenguaje; dicción contemporánea; infinito humano.

\section{Introdução}

Há, em todos os atos humanos, uma questão de linguagem. Por isso - e repetidas vezes - Octávio Paz (1984), com ênfase, assegura: o “homem” é a própria linguagem. Poder-se-ia dizer de maneira diferente: a linguagem é o ser humano em seu devir, em suas lutas no campo da política, do trabalho, dos afetos. Ao dizer o sujeito chega ao Outro e, em chegando, se constitui; essa constituição nunca é total, nunca será completa e jamais será neutra.

Consoante às labutas de aprendizagens e às esferas delicadas e complexas da cognição, três atividades diárias, essenciais do trabalho intelectual - a leitura, a escrita e o pensamento são sustentadas pelo devir da linguagem. Ou melhor: pela linguagem em devir. Ora, aquele que lê, lê o que alguém escreveu; o que escreveu o fez porque antes leu. Escreve-se sobre objetos do mundo; lê o que pensou sobre o que alguém escreveu sobre objetos do mundo. Pensamento e mundo se enovelam. E se pressupõem. Assim, a linguagem se faz e faz o mundo.

Face a isso, pode-se sintetizar: a batalha da vida é uma batalha de linguagem. O dizer é um campo para que se estabeleça relações com o Outro, e esse Outro, a quem se dirige, é, num só tempo, espelho e condição de toda fala. Como quer Orlandi (2018), não há opacidade na linguagem, tudo fala: objetos, cores, o céu cinza ou azul, a fachada da casa, o tom sublime da reza do devoto, o clamor do pedinte, o gesto do vendedor de melancia, a mercadoria espetacularizada no Shopping Center. O ser humano fala dormindo, em silêncio, nas cantorias de morte e nas comemorações de pequenas ou grandes vitórias. E o dizer diz o ser humano que fala. Revela-o, declara-o. Clarice Lispector (1999), aborda esse vaticínio humano: “As palavras 
me antecedem e ultrapassam, elas me tentam e me modificam, e se não tomo cuidado será tarde demais: as coisas serão ditas sem eu as ter dito" (1999, p.74).

Como fato de cultura e como processo humano, a linguagem medeia todas as relações sociais. E todas as mudanças sociais implicam na efetivação da linguagem, no seu teor quente, nas suas artimanhas e astúcias. Por meio desses princípios construímos a problemática desse artigo: quais são as implicações ocasionadas pelas sociedades mundializadas na linguagem? Essa pergunta faz suscitar outras: é possível estabelecer identidades discursivas originadas neste período histórico, especialmente no Brasil atual? Como edificar uma dicção pedagógica que valorize o diálogo, a escuta, a interrogação como artificies da intersubjetividade?

Partimos de um pressuposto: as sociedades mundializadas atingem as dizibilidades de várias maneiras, nos meios - e nas mensagens; nas ideologias e nos hiatos; nas formas como os meios ajudam a estabelecer as relações sociais; nos gêneros textuais e discursivos; na sintaxe; no léxico. Na semântica. E é próprio desse período patentear dizeres narcísicos, escapatórios, agressivos. A valência dialética parece ser essa: nenhuma transformação social ocorre sem a mudança da linguagem, a linguagem é artesã das mudanças sociais. $\mathrm{O}$ espectro conservador do Brasil atual, por exemplo, distende a integridade ética do dizer, dissolve a confiança na palavra. Abre-a à estupidez.

Dessa feita, expedientes como blogs, sites, mensagens virtuais; selfies; memes; e-mails - e tantos outros, colocam a palavra escrita numa profunda circularidade. A escrita entra direta e recorrentemente na sociabilidade humana, em namoros; nas receitas virtuais de cozinha; na efetivação do trabalho; na realização de pesquisas e também nos plágios; nas condutas estilísticas da textualidade acadêmica e, especialmente, na organização da memória, da percepção e da cognição.

Com o objetivo de interrogar o modo pelo qual a cena cotidiana no Brasil e os desafios da formação acadêmica e pedagógica se cristalizam perante os arroubos complexos das sociedades mundializadas, propor-se-á as reflexões que virão. O tom crítico da proposta de reflexão - como sendo a gravidade lustrosa do trabalho intelectual - esposa-se numa assertiva: mesmo que haja dizeres empobrecidos no seio acadêmico e dizeres fascistas na verve popular e nos agentes que dominam o Estado brasileiro, a linguagem é o possível do humano; essa possibilidade - incorrigível e implacável e aberta - é essencialmente política: os iguais podem se juntar; podem rebelar, podem, por isso, gritar por liberdade. Gritar é uma metáfora, o que se quer é atitude: palavras de combate, palavras de amor. Ações. 


\section{Um passeio no mundo da linguagem}

Barthes (2001), com destemido argumento, apregoa que o sujeito moderno não cessa de ler. Acometido pela linguagem, usufrui dela para agir e decifrar os sentidos de sua própria ação. Lê sem parar: lê bula de remédios; lê placas de trânsito; lê notícias econômicas; lê as circunstâncias, o espaço e a si mesmo. Com semelhante argumento a linguista Eni Punccineli Orlandi (2018) disserta que,

Saber ler-e-escrever é uma injunção, uma obrigação, em nossa sociedade letrada, ocidental, cristã. Mas pode-se olhar por outro lado e vemos, então, que é também uma necessidade para o sujeito: é o jeito que ele tem de significar o mundo, se significando nele. E saber "dar" sentido ao que ouve, ao que lê, ao que vê (ORLANDI, 2018, p.223).

De maneira direta, como argumentou Orlandi, a ação intelectual e a condição acadêmica - e também a possibilidade de ser sujeito-do-mundo, engajado no espaço/tempo, colocam as leituras e as escrituras como centro da sociedade ocidental. Entramos no baile do mundo decifrando-o ou não. Lemos um livro por meio de formas/tipos de leituras impressas numa época e tensionados pelos conflitos ideológicos que se nos implicam.

Por conseguinte, a luta para compreender a significação de um texto é, no fundo - e sempre, - a luta para compreender a realidade de um tempo. Os textos, os nossos escritos; a leitura, as nossas construídas, falam de objetos do mundo. Tentamos interpretar o mundo pelos objetos. Por isso, que a linguista Orlandi (2018), com inteligência, sintetiza: a busca da significação supõe o conhecimento das relações de força que comandam e hegemonizam certa estrutura social. O dizer requer um compromisso porque indefensavelmente é tramado com ou contra as forças ativas do tempo. Quem comanda o objeto e sua significação é o processo social.

Por isso, lemos e escrevemos palavras-mundos.

Nessa vertente um pressuposto tem sido colocado como premissa política na referência à linguagem: toda luta política é uma luta epistêmica. Ao fazer a defesa de uma "desobediência epistêmica”, Walter D. Mignolo (2008), revela que,

A opção descolonial é epistêmica, ou seja, ela se desvincula dos fundamentos genuínos dos conceitos ocidentais e da acumulação de conhecimento. Por desvinculamento epistêmico não quero dizer abandono ou ignorância do que já foi institucionalizado por todo o planeta (por exemplo, veja o que acontece agora nas 
universidades chinesas e na institucionalização do conhecimento). Pretendo substituir a geo- e a política de Estado de conhecimento de seu fundamento na história imperial do Ocidente dos últimos cinco séculos, pela geo-política e a política de Estado de pessoas, línguas, religiões, conceitos políticos e econômicos, subjetividades, etc., que foram racializadas (ou seja, sua óbvia humanidade foi negada). Dessa maneira, por "Ocidente" eu não quero me referir à geografia por si só, mas à geopolítica do conhecimento. Conseqüentemente, a opção descolonial significa, entre outras coisas, aprender a desaprender (como tem sido claramente articulado no projeto de aprendizagem Amawtay Wasi, voltarei a isso), já que nossos (um vasto número de pessoas ao redor do planeta) cérebros tinham sido programados pela razão imperial/ colonial. Assim, por conhecimento ocidental e razão imperial/ colonial compreendo o conhecimento que foi construído nos fundamentos das línguas grega e latina e das seis línguas imperiais européias (também chamadas de vernáculas) e não o árabe, o mandarim, o aymara ou bengali, por exemplo. Você pode argumentar que razão e racionalidade ocidentais não são totalmente imperiais, mas também críticas como Las Casas, Marx, Freud, Nietzche, etc (MIGNOLO, 2008, pag 290)".

Os argumentos de que as transformações sociais são epistêmicas e de que há um caráter geopolítico na produção do conhecimento e, inclusive, de que há um domínio linguístico na sedimentação dos impérios ocidentais, mostram que toda mudança individual ou social supõe uma crítica de linguagem. As esferas de dominação, conforme aludido, agem por meio de inferiorização, apagamento e silenciamento de outros modos de dizer a realidade. A reação contra as opressões sutis ou imperiais, portanto, requisitam uma rebeldia de linguagem, ou a libertação da palavra para que, com autonomia, a nossa palavra deixa de ser a palavra do Outro. Pode ser a nossa palavra com a do Outro, juntas e reforçadas, irmanadas de sentidos e visões semelhantes da vida e do mundo.

Numa direção próxima o semiólogo Roland Barthes (2001), ao perscrutar a força da narrativa na experiência humana, sintetiza que "toda matéria de vida é matéria de contar histórias”. Barthes com força poética destaca que,

Inumeráveis são as narrativas do mundo. É de início uma variedade prodigiosa de gêneros, eles próprios distribuídos em substâncias diferentes, como se toda matéria fosse boa para o homem confiar-lhe a sua narrativa: a narrativa pode ter como suporte a linguagem articulada, oral ou escrita, a imagem, fixa ou móvel, o gesto e a mistura ordenada de todas essas substâncias; está presente no mito, na lenda, na fábula, no conto, na novela, na epopeia, na história, na tragédia, no drama, na comédia, na pantomima, no quadro pintado ( pense-se no Santa Úrsula de Capaccio), nos vitrais, no cinema, nas histórias em quadrinhos, nas notícias de jornal, na conversa. Além disso, sob essas formas quase infinitas, a narrativa está presente em todos os tempos, em todos os lugares, em todas as sociedades; a narrativa começa com a própria história da humanidade; não há, não houve em algum lugar povo algum sem narrativa; todas as classes, todos os grupos humanos têm as suas narrativas, e muitas vezes essas 
narrativas são apreciadas em comum por homens de culturas diferentes, até mesmo oposta; a narrativa zomba da boa e da má literatura; internacional, trans-histórica, a narrativa está sempre presente, como a vida (BARHES, 2001, p.103/104).

A força da narrativa e a sua presença nas coisas humanas e sociais, tão bem caracterizada por Barthes, incorpora o que, com consistência, é uma baliza teórica de nossas formulações, especialmente pela contribuição prodigiosa e criativa da professora Angelita Pereira de Lima, da Faculdade de Informação e Comunidade, da Universidade Federal de Goiás. A partir de leituras de Bakhtin, especialmente as analisadas por Brait (2013), e Benjamim (2009), o pressuposto é esse: não há experiência sem a narrativa e toda narrativa, não apenas faz a experiência ser vivaz, mas a constitui como memória. A memória é a seiva da história, recurso mediante o qual a significação do tempo esclarece quem domina e quem é dominado. A conclusão é peremptória: a memória é política. A narrativa é a artesã da memória, esse móvel robusto da consciência histórica.

Barthes (2001), com a sua razão, ao preconizar "que toda matéria de vida é matéria de contar história", ilustra o valor político da experiência como fonte de narração. Vê-se que nas sombras incandescentes de sua formulação, a narrativa não se separa da vida, a vida toda é um fato verbal ou linguístico. Dizer o mundo, enfrentar as mentiras e contar a própria história sabendo o lugar de quem conta, é um reconhecimento do sujeito como sujeito histórico; é um conhecimento da vida como um atributo histórico. Assim, a experiência, por mais singular ou individual, na situação espaço-temporal em que se efetiva, traduz-se numa experiência coletiva, aberta à linguagem, aberta à retomada da consciência. Esse sentido de abertura tece o ser humano determinado social-historicamente, nunca preso, pois age também no possível.

A formulação de Carlos Nelson Coutinho (2000), após cerca de 50 anos de pesquisa mirando a relação entre sociedade brasileira e cultura, encontra eco nos princípios de Barthes e, especialmente, nas densas reflexões de Gramnsci (2013 ). Ao defender que formas e ideias são, ao mesmo tempo, expressões e maneiras de constituição do real e que, no Brasil, a elite representou e representa a cultura como um mero ornamento, dedicando ações de desvalorização da cultura popular, o autor demonstra que não há consciência social, nacional e cultural, fora da batalha das ideias. Em constante batalha é que se torna possível a identificação da realidade do trabalhador, do negro, da mulher, dos povos indígenas. A identificação é o suposto para a transformação social. E para enfrentar preconceitos, estigmas, golpes de apagamento e de inferiorização. 
O problema central para a identificação do trabalhador - e de todos es "esfarrapados do mundo", conforme incide a tese freiriana (2011), é quando o oprimido hospeda os valores dos opressores em sua consciência. Pensar a partir da classe com os da mesma classe e para a classe oprimida requer, assim, esse combate às formas e ideias elitizadas. Portanto, é tarefa da educação escutar o trabalhador; é tarefa do trabalhador contar a sua história, reconhecer-se nela e por ela efetivar os seus propósitos de classe, o seu sentido de vida.

\title{
2 As sociedades mundializadas e a convulsão simbólica
}

O economista francês François Chesnais (1996), foi um dos primeiros, no plano teórico, a repudiar a ideia de globalização que, subliminarmente, produzia uma ideia que só existiria a possibilidade de um projeto econômico para o mundo: o neoliberalismo. Ao analisar a força do capital financeiro e a maneira pela qual a acumulação capitalista, por meio de bolsas de valores, faziam transitar trilhões de dólares retirando capitais do setor produtivo, o autor estabeleceu uma crítica ao vocábulo "globalização", substituindo-o pelo vocábulo "mundialização". Procedendo assim, abriu as portas para se pensar outros campos do tecido social. A sua explicação é resumida: “[...] certos momentos em que numerosos fatores desembocam num novo conjunto de relações internacionais e internas, que 'formam um sistema' e que modelam a vida social, não apenas no plano econômico, mas em todas as suas dimensões. (CHESNAIS, 1996, p. 14)".

A sua explicação possui um timbre histórico. Diz ele que,

\begin{abstract}
A mundialização é o resultado de dois movimentos conjuntos, estreitamente interligados, mas distintos. $\mathrm{O}$ primeiro pode ser caracterizado como a mais longa fase de acumulação ininterrupta do capital que o capitalismo conheceu desde 1914. O segundo diz respeito às políticas de liberalização, de privatização, de desregulamentação e dedesmantelamento de conquistas sociais e democráticas, que foram aplicadas desde o início da década de 1980, sob o impulso dos governos Thatcher e Reagan. (CHESNAIS, 1996 p. 34).
\end{abstract}

Interessa-nos nas reflexões sobre a batalha de linguagem o modo pelo qual as sociedades mundializadas, por meio de redes moduláveis e do incremento científico e tecnológico, foram capazes de mexer na estrutura espaço-temporal. E também nos alicerces do conhecimento científico, na percepção humana e no processo de exploração, significação e recriação artificial da natureza. 
Imagens de satélites, mapeamento de DNA - ácido desoxirribonucleico -, combinação de gens, formação de banco de dados e tantos outros objetos, atividades e incrementos simbólicos, são responsáveis por criar um dilúvio de informação e de imagens. Esse expediente implicou vorazmente no papel da linguagem, em sua estrutura e em sua funcionalidade. A palavra escrita, por exemplo, tal como foi advertido, passou a fecundar a sociabilidade, muitas vezes, envenenando-a.

No plano objetivo, a transformação da economia num grande cassino global de capitais; a sua comoditização; a luta pelo controle das bancadas políticas que facilitam a operação do livre comércio; o crescimento do desemprego estrutural; a financeirização da pobreza e a segregação urbana, foram capazes de elevar a instabilidade como marca de um tempo. No plano simbólico essa instabilidade grita, comove, gera desesperos.

Tudo isso num tom acelerado. A aceleração funda e se funda pela hipermobilidade que ocorre também no plano das transações simbólicas. Signos, os mais diversos e contrastantes, atravessam os lugares e os sujeitos. O turbocapitalismo acendeu o pavio do capitalismo cognitivo e transformou a esfera simbólica em vício e em receptáculos de traumas históricos e de mágoas intrusivas. Falar tudo de tudo ao mesmo tempo, recebendo e aspergindo signos de diferentes ordens de visão de mundo, implementou uma convulsão simbólica atinente a um mundo em alta voltagem.

Cada lugar sendo fotografado por satélites, cada sujeito hospedando uma imensa quantidade de informação, tendo pouco tempo para refletir, a informação batendo como fragmento e pó no cérebro, são móveis que conduziram o sujeito a ser operário e refém da convulsão simbólica. Aturdido e atônico, eufórico e viciado, afeito aos impulsos das imagens e compulsivo, ainda sim, o sujeito desse tempo pode se beneficiar desse regime on-line, Ora, houve o aumento das possibilidades de comunicar; abriu-se fontes e arquivos bibliográficos ao grau infinito; cresceram as condições de intercâmbio, de comunicação e, portanto, de criar.

Em palavras curtas e diretas há que saber: a linguagem, como esfera simbólica, mesmo implicada social e determinada por forças de domínio cultural e econômico, escorrega das mãos dos opressores e se coloca como dádiva do infinito humano. Isso pode ser patenteado: o ser humano, ser de linguagem, acede ao mundo com irrefreáveis condições de criar, amar, transformar. O infinito simbólico é o infinito humano, afiguração do mundo e de possibilidades. Porque o humano é possível nenhuma castração cerceia a sua capacidade de insurgir. Muitas 
vezes a insurgência é fina, silenciosa, entranha as margens e dela monta o combate da esperança. Quando se vê o despotismo esfacela-se como farelo de cristal quebrado.

\section{Traços da dicção contemporânea}

Como foi exposto, brota, no atual período, uma profunda circulação de informações. Signos verbais e imagéticos são lançados aos milhares em segundos; alteram-se a forma das relações; crescem as fontes que disseminam as ideologias, vejamos o debate sobre os fake News. O apressamento é a lógica. Esse mundo em alta voltagem cria uma espécie de terremoto de signos tecido por um dilúvio de informação e pela tempestade de imagens.

Rolnik (2018), explica: cada vez mais deixamos de ser o que somos, daí a dificuldade de saber o que está acontecendo, pois somos defasados da própria experiência. Como se tem dito, o vivido é atravessado por peças alhures. Há casos em que mora em nós eus estranhos.. A vida, como um negócio diário, fita o Outro no foco estratégico desses negócios.

Impulsos, compulsões, fragmentação, desesperança, delírio, fascismo são termos dessa sociabilidade envenenada e traços da dicção contemporânea. Mais: nesse quadro atabalhoado é comum o destempero dos prazos, a frouxidão ética, a edificação de uma escrita policiada e de um pensamento enformado de clichês e slogans. Dessa feita, o embaralhamento dos signos é expressão do embaralhamento do sujeito, este funda aquele. E ambos se completam num único termo: vulnerabilidade.

Sob, com e perante as tensões dessa sociabilidade, é que alçamos, na Universidade - e fora dela - a nossa palavra. A questão parece então não ser apenas o fetiche do discurso, marca do professor universitário (do padre e do pastor), mas o modo de procedê-lo, o viés de seu conteúdo. A textualidade predominante e hegemônica, encetada pelo comércio do discurso,

cai fácil no essencialismo abstrato. É característica dessa identidade discursiva - o essencialismo abstrato - as repetições empoladas de conceitos, a subtração da experiência e do acontecer do mundo.

Da mesma maneira, especialmente a força da pós-graduação e o regime de vigilância imposta pelos órgãos de financiamento constitui o comando do formalismo. Dele provém textos adestrados, cosmésticos, burocráticos, laboratoriais - pobre de imagens; repetidos; entregues aos jargões e, por isso, distantes da experiência. Esses textos são marcas de um pensamento empobrecido e de uma dicção aprisionada. Libertar a dicção é libertar a própria vida. 
Diante desse quadro, o nosso desafio é problematizar o discurso de pesquisa, pois a ciência, caso queiramos a liberdade, não pode ser uma válvula de escape. Ela existe para implicar, para imaginar, para criar. Em muitos casos, para povoar o silêncio de inquietação benévola e bela. O desafio, conforme assinala Rolnik (2018), é gerar a vitalidade de um pensamento que agrega e se opõe às forças que sequestram a potencialidade criativa do ser humano. O sujeito em agregação não perde o êxtase do encontro. Ao interrogar as origens e as causas das mazelas sociais, psicológicas e humanas, o sujeito pode encontrar o semelhante.

Fora dos circuitos acadêmicos explodem e se disseminam narrativas ácidas, expressivas do ceticismo da época. Muitos gêneros são fragmentados; as modalidades estilísticas e discursivas encantam-se pelo deboche, pela ironia, pelo pastiche e, especialmente, pelo desrespeito à fala do Outro. Evasivas, sloganização, formalismo, sadismo e ameaças penetram o território de uma parte dos discursos populares e de várias instituições, inclusive, de agentes do comando jurídico e do Estado brasileiros.

Num esforço de síntese é possível estabelecer identidades discursivas acompanhadas de valores que as nutrem.

\section{a) o formalismo academicista}

A criação, expansão e disseminação da pós-graduação no Brasil tem sido responsável por instituir uma identidade discursiva: o formalismo academicista. Os textos de dissertações e teses, manietados no habitus da pressa, se caracterizam pelas citações; pela intromissão da ABNT - (Associação Brasileira de normas técnicas), por fórmulas que, pelo mecanismo da repetição, tornam-se um habitus de escritura. Essas fórmulas geralmente expurgam dois componentes do processo criativo: a experiência e a imaginação.

Em muitos casos as citações, recurso de idoneidade ética, se colocam apenas como erudição disfarçada. O que é mais central, a interlocução teórica, o diálogo com autores clássicos ou mesmo com autores presentes nos contextos de produção, podem se arrefecer burocraticamente pela citação. Citar não é um problema; pode ser o que é mais humano na produção intelectual: o sentido coletivo do que se faz, o encontro de gerações por meio da palavra escrita e da leitura. Entretanto, a citação burocratizada, ao invés de sedimentar o diálogo, o impede; impedindo-o cria castelos de isopores, ou seja, às vezes os autores citados são sofisticados em seu sistema de pensamento, mas aparecem apenas como cifras fragmentadas de uma textualidade insossa. E sem autonomia criativa. 
O formalismo, fundado no apelo do conceito e das teorias, sustentado por indicadores e falácia de autoridades, no habitus da pressa, toma lugar da reflexão. Em muitos casos, suscita dessa identidade textual uma confusão entre rigor conceitual e adestramento textual. $\mathrm{O}$ autor, posicionado na condição de administrador de um formato, que, por sua vez, advém de uma cultura textual aceita, incentivada e avaliada numa rede de poder, desde os arguidores de bancas de defesa até o banco mundial, que estipula projetos de educação para o mundo inteiro, se entrega ao sistema sem deliberar.

A "nobreza" da conquista dos títulos e o equívoco de terceirizar o seu pensamento, a sua experiência e sua potência criadora, muitas vezes faz o sujeito encadear discursos formalmente revolucionários e libertadores, inclusive com slogans marxistas ou de outras ordens filosóficas e políticas do denominado pensamento de esquerda. Contudo, no plano estreito do formalismo academicista, o brado revolucionário e libertador, pode promover apenas uma espetacularização para, no pleito do habitus reinante, domar a plateia, filiar-se a um jogo de poder que, na raia discursiva aparenta rebelar contra os poderes instituídos, mas no conteúdo das práticas e das atitudes, prosterna-se ou mantém vivas as ideologias machistas, falocráticas e de negociações espúrias. É fácil nesta conduta confundir ética e controle, regra e reprodução, discurso e práxis.

Quando o escritor paulista Juliano Peçanha (2006), solicita para tirar as dores do pote de conserva, o mesmo pode ser solicitado concernente ao texto acadêmico: convém tirar os textos do pote de conserva. Isso não quer dizer que se deva desmerecer o rigor conceitual e o alcance da teoria na interpretação dos objetos do mundo, das situações e dos eventos da vida. Significa contrapor-se ao adestramento textual sem cair na performtização, daí, mestrandos, doutorandos, orientadores pouco falam, por exemplo, das dores, dos erros, das tensões pelas quais suas trajetórias de formação enfrentam.

Tensionar e enfrentar as textualidades, as identidades discursivas e as performances textuais são meios para conceber e instituir o pensamento como condição inalienável, a partir do qual o sujeito luta por autonomia. Quando Merleau Ponty (1999), assegura que cada gesto, cada palavra, cada expressão, é primordial, está, também, revelando a primazia do pensamento como fonte de vida - e de transformação.

\section{b) a militarização do dizer}


O clima beligerante, propalado por ordens do poder dominante em caráter geopolítico internacional e nacional, ganha a verve popular e torna-se expressão paradigmática de uma forma de ler o mundo. Trata-se do que Pelbart (2003), denomina "militarização da existência". Como uma espécie de antídoto contra a violência social estampada no tecido social inteiro, o paradigma da militarização é declarado em outros campos da vida, como nos muros e nas fortalezas que protegem condomínios fechados; na militarização de escolas públicas; na mercantilização de seguros; na fabricação de veículos com proteção à balas.

Numa tabela mercantil com a fobia social generalizada, também com o comércio da dor e com a espetacularização do sofrimento, fartamente transformados em programas de TVs, as cenas reais da violência - e do sofrimento - incrementam discursos sensacionalistas, moralistas, justiceiros. O mesmo ocorre com a militarização do dizer. Baseando-se num apelo moral, fundamentando no ódio e na mágoa de vida, caracterizando-se por ameaças e insultos, além de restituírem visões dicotômicas entre bom e mal, apela para o salvacionismo e para o mitificação de heróis.

A beligerância do dizer, conforme ponderou Tiburi (2015), geralmente é um atributo de sujeitos autoritários, ou seja, daqueles que não consideram o diálogo como forma de conviver, debater diferenças, construir o discernimento dos eventos que lhes tocam. Com desprezo ao diálogo, a beligerância dos sujeitos autoritários, é uma declaração de fragilidade. Desqualificar o Outro com discurso autoritário e não permitir que Ele diga a sua palavra, o que parece força da voz é apenas a fraqueza para ouvir. Embora essa postura autoritária é inócua, pois não é possível castrar a mobilidade dos símbolos, nem ceifar o pensamento e as ideias. O moralismo com solução pela violência revela a situação problemática do moralista. Revela a sua fragilidade.

\section{c) o esotérico-metafísico}

Uma das identidades discursivas proeminentes neste período refere-se ao crescimento de seitas, facções, grupos religiosos e esotéricos. A literatura de auto-ajuda, as correntes de ajuda e de salvação; e o empreendimento rápido e estratégico de vários grupos religiosos recolocam o debate entre razão e irracionalismo; entre realidade histórica e salvação. Fazendo uso de mídias, TVs, e lastreando-se nas periferias urbanas e no seio da classe trabalhadora, incentivando o comércio da esperança a partir da agregação de irmandade, esse discurso penetra 
as escolas, ressacraliza a ação pedagógica, entra nos movimentos sociais, faz pacto com as bancadas conservadoras do congresso nacional e anima a ideologia da prosperidade e liberal.

A agregação de irmandade, mediada pelo discurso salvacionista do além-mundo, apazigua ou esconde a luta de classes e distende-a no seio da consciência do trabalhador. Além de criar a mente culpada, pois o insucesso individual é configurado como falta de oração e como pouco esforço de ajuda na obra, esse discurso se traduz numa ideologia individualista e liberal. O apreço pelo guru ou pelo líder religioso assenta-se no lugar da leitura coletiva.

A fuga da consciência da história e o seu ajuste pela via sacra produz uma visão de mundo interessante aos grupos que dominam a economia e geram a desigualdade social, o empobrecimento e a fome. O deslocamento do mundo de muitos fieis, signatários e membros, faculta o enriquecimento de líderes, seu poder concreto na ligação com o Estado e com as forças de domínio geopolítico do mundo. A evangelismo de prosperidade financeira não debate essa sociedade, afeiçoa-se a ela. Não raras vezes, silencia-se sobre as causas sociais geradoras da desigualdade social, da violência, do adoecimento, da erosão genética, da extinção de espécies, da contaminação dá água e de alimentos.

A estreita relação entre carisma, liderança e força dos líderes com o poder instituído, ajuda a conservar o modelo de desenvolvimento econômico e a geopolítica fundada em guerras, exploração do trabalhador e humilhação de classe. Zizek (1996), ao pronunciar o dever de combater o guru e o consumismo reconhece que se encontra em desvelo a ideologia liberal global, essa que seduz o trabalhador para deixar o mundo como está, apagando a necessidade de ler as contradições sociais.

Junta-se a essas identidades discursivas, a força do discurso do empreendedorismo que possui ligação efetiva com o consumismo e com a verve pós-moderna. Enquanto o primeiro impetra o valor liberal, e põe tudo na conta do esforço e na inteligência do indivíduo, propagando a importância da qualificação, o segundo impetra o niilismo, a adesão ao esgotamento, o elogio ao acaso, à incerteza, A promessa de riqueza do primeiro grupo recebe o pouco caso do segundo, inclusive, a desvalorização das formulações passadas. Assim, a identidade pós-moderna se encanta pelo pastiche, pela ironia, pelo sadismo.

Num trabalho de pesquisa cujo o objetivo era o de ouvir a juventude da escola pública da periferia de Goiânia foi possível gerar uma cartografia de falares jovens. Ao construir uma espécie de cartografia urbefônica da periferia metropolitana, detectou-se a prevalência de falas em torno da crença cristã. Formando um território de fala, especificamente os evangélicos, 
costuram também relações de afeto, de aproximação e de namoro entre os membros desse território.

Outro grupo de jovens, com palavras mundanas, exerce a fala em torno do salário de jogadores de futebol; de sonhos em ser jogadores, ou de cuidado com o corpo e sonhos de consumo; em ser manequim, modelo, vedete de TV. Muitos membros desses grupos elegem ídolos ao modo de referências vulneráveis. Há o grupo que, próximo a esse, estende os seus gestos e suas falas acerca da cultura jovem, comentam grupos de Rappers, bandas de rock, séries de TVs, músicas que sacolejam a sua percepção e a sua emoção. Há o grupo que, em silêncio, em sua resignação, esconde feridas vivas de separação de pais, problemas com irmãos aprisionados, desemprego na família. Constroem silêncios grávidos de dor. Somente com uma aproximação afetiva é capaz de lhes motivar a abrir a boca; e há os que, estabanados, presos nos vícios pelas redes, entranham o mundo infoviário e escapam das cirscunstâncias. Mas há os que se encantam pelas lutas no campo dos coletivos de mulheres negras ou de Movimentos Sociais Urbanos, estudantis.

Os diferentes falares desenham diferentes territórios; esses territórios são a carne viva, a brasa da palavra, um pouco do que lhe restam no mundo. Narcísicos ou ansiosos, entediados ou humorados, melancólicos ou agitados, depressivos ou bravos, sujeitos e falas documentam o mundo espacialmente constituído. A sua fala é o mundo dito com tudo que compreende a ambiguidade da palavra: revelar e esconder.

\section{Um pouco de considerações}

Um mundo em alta voltagem. Acelerado, livre para o capital, com muros para o trabalho. Feito e refeito por crises iminentes, constantes. Bélico. E com profunda monopolização de riquezas e bens. Atravessado pela hipermobilidade de capitais, mercadorias e símbolos transformando a arena econômica num grande cassino global. Implementado pela ação direta da ciência e da tecnologia que, juntas, atravessam as esferas da produção, da sociabilidade, da organização dos afetos e dos desejos. Neste mundo concreto a circulação de signos se evidencia como uma majestosa - e complexa - babel.

Junto à economia, às relações de produção e à sociabilidade, os agentes dominantes, como o mercado, as máquinas de guerra, as religiões, disputam o desejo, o corpo e o tempo livre da juventude. Esculpem novas ideologias, como a estetização da existência configurando a esteticomania; o narcisismo de classe, configurando o hedonismo; a agregação metafísica configurando o evangelismo financeiro. 
A babel simbólica, a rede em permanente transação, a mistura de visões de mundo e a fragmentação do trabalho, constituem a convulsão simbólica. Sob convulsão cada vez se torna mais difícil o sujeito deste tempo saber quem se é e, portanto, o que quer, para onde está indo. A convulsão simbólica cria um solo social trepidante, complexo e conectado. Carente mas narcísico, adoecido mas petulante, esse sujeito embrenha-se no mundo e afasta de si. Dentro de si afasta-se do mundo. Perplexo faz do vício a última saída, e a fuga metafísica a declaração da sua fragilidade.

Nessas condições históricas a linguagem é vorazmente implicada. Isso ocorre no formato dos gêneros literários, por exemplo, ressalta a autoficção; a literatura confessional como biografias encomendas; a esotérica e de auto-ajuda; surgem textos interativos; hipertextos. Alteram-se o ritmo da linguagem, produzem-se síncopes, justaposições. Os textos se tornam curtos, atomizados. Contudo, os meios e os suportes facilitam o exercício de ler, escrever; juntam-se, no mesmo expediente, textualidades escritas, orais, não verbais. Tudo isso atua na memória, na percepção, no tempo da escrita. Está instaurado um novo regime cognitivo. A linguagem é o cerne.

Lógico que os bancos de dados, os atlas eletrônicos, o arquivo incomensurável de textos na internet; as bibliotecas eletrônicas; os tradutores eletrônicos; os ebooks alargam as fontes, permitem maiores acessos, encurtam as possibilidades de intercâmbio, aumentando o possível do humano. Mais conectado com o mundo e com a mente desconexa, com informações ilimitadas e com limites de reflexão, a questão central do sujeito é a mesma: como produzir sentidos no ato de escrever, ler e pensar?

A força dos dispositivos simbólicos na realização da vida humana é o que sujeito conta para ler o mundo: como explicar a riqueza de informação e a precariedade da vida social? Como explicar o grau máximo de organização lógica na ciência e na tecnologia e o irracionalismo crescente na visão de mundo? A linguagem, com todos os seus componentes, ambiguidades e possibilidades, não se rende. Mesmo que haja um embaralhamento para ler o tempo e para efetivar um superego com integridade ética; mesmo com o trabalho e a emoção sendo peças de uma submissão estruturada, o adágio se faz legítimo: só nos resta a linguagem. E só ela é tudo.

É com a linguagem e pela linguagem, em diálogo, que constrói-se a possibilidade de desestabilizar as formas de dominação; organizar o enfrentamento; salmodiar alegria em tempos difíceis; implicar-se no campo micropolítico e fazer da alegria uma dimensão ética. Conforme apregoa Rolnik (2018), não se pode correr do mal-estar. Quando se ampara na 
linguagem para falar do mundo e fazer de si a ponte para que essa fala seja escutada, relacionar com o Outro e potencializá-lo, é uma forma de fermentar a própria potência. Mas como a linguagem é ambígua, ambiguidade poeticamente revelada por Leminski (1980 ): “repare bem no que não digo”, qualquer vacilo no modo de empenhar a fala ao Outro gera complicação; qualquer vacilo no dizer o mundo complica-se a verdade e, daí, o resto, a vida se torna um equívoco.

Quando Arroyo (2012), defende a humanização dos espaços do viver e observa a reivindicação de fala, de formas de narração e de estilos de dizer dos Movimentos Sociais, dos coletivos femininos, de povos quilombolas e indígenas, o convite é para que se faça da linguagem uma ação: o contágio mobilizador. O dizer posto como flor de combate e de coragem requisita lucidez, amabilidade, um desvio da estupidez, da chantagem, do vitimismo, da mágoa. A palavra boa aos bons, a palavra de combate aos ruins, como refere-se o escritor baiano Alan Machado (2015), é o caminho para um porre de liberdade.

\section{Referências}

ARROYO, Miguel. Outros sujeitos, outras pedagogias. Petrópolis- RJ - Vozes, 2012.

BARTHES, Roland. A aventura semiológica. São Paulo: Martins Fontes, 2001.

BENJAMIN, Walter. Ensaios reunidos: escritos sobre Goethe. São Paulo: Duas Cidades: Ed. 34, 2009

BRAIT, B. (org.) Bakhtin, dialogismo e construção do sentido. 2. ed. Campinas, Editora da Unicamp, 2013.

CHESNAIS, F. A mundialização do capital. São Paulo: Xamã, 1996.

COUTINHO. Carlos Nelson. Cultura e Sociedade no Brasil: ensaios sobre idéias e formas. Rio de Janeiro: PD\&A, 2000

FREIRE, Paulo. Pedagogia do Oprimido. 50 ed. São Paulo: Paz e Terra, 2011.

GRAMSCI, A. Cadernos do Cárcere. Edição Carlos Nelson Coutinho. Rio de Janeiro: Civilização Brasileira, 2013. Volume 1.

LEMINSKI, Paulo. Haikai de Paulo Leminski. In. O Pensador. Acessado em 05.08.2019: https://www.pensador.com/autor/paulo_leminski/ 1980.

LISPECTOR, Clarice. A legião estrangeira. Rio de Janeiro: Rocco, 1999.

MACHADO, Alan, O. Para dizer que foi assim: histórias, memórias e outras invenções. IBICARAI - BA: Via Litterale, 2015.

MERLEAU-PONTY. Fenomenologia da Percepção. São Paulo: Martins Fonte, 1999. 
MIGNOLO, Walter D. Desobediência epistêmica: a opção descolonial e o significado de identidade em Política, in: Cadernos de Letras da UFF, Dossiê: literatura, língua e identidade, Niteroi-Rj, 2008, pag 287-324.

ORLANDI, Eni, P. Entre letras, o mundo. In: ENTREMEIO - Revista de Estudo do discurso, 2018, pag 219-227

PAZ, O. O arco e a lira. Rio de Janeiro: Nova Fronteira, 1984.

PEÇANHA, Juliano G. Certeza do Agora. São Paulo: Ateliê editorial, 2006.

PELBART, P.P. Vida capital: ensaios de biopolítica. São Paulo: Iluminuras, 2003.

ROLNIK, Suely. Esferas da Insurreição - notas para uma vida cafetinada. São Paulo: N-1 edições, 2018.

TIBURI, Marcia. Como conversar com um fascista: reflexões sobre o cotidiano autoritário brasileiro. Rio de Janeiro: Record, 2015.

ZIZEK, S. “O Espectro da Ideologia”. In: Um mapa da ideologia. Rio de Janeiro: Contraponto, 1996.

Recebido em 23 de setembro de 2019 Aceito em 14 de novembro de 2019. 